\title{
Uptake of intermittent preventive treatment for malaria in pregnancy among women in selected communities of Ebonyi State, Nigeria
}

Christian Obasi Akpa ${ }^{1,2,3}$, Joshua Odunayo Akinyemi ${ }^{2}$, Chukwuma David Umeokonkwo ${ }^{1,3^{*}}$ (D), Eniola Adetola Bamgboye ${ }^{2}$, Tukur Dahiru ${ }^{4}$, Ayo Stephen Adebowale ${ }^{2}$ and IkeOluwapo Oyeneye Ajayi ${ }^{1,2}$

\begin{abstract}
Background: Malaria in pregnancy has adverse effects on maternal and child health. Intermittent preventive treatment (IPTp) with three doses of Sulfadoxine/Pyrimethamine is an effective preventive measure for malaria in pregnancy. However, 24.0\% of women use this prophylactic regimen in Ebonyi State. Previous studies have focused on the level of uptake with less attention given to factors influencing uptake. Therefore, we examined the predictors of IPTp uptake in the last pregnancy among women in Ebonyi State, Nigeria.

Methods: This was a community-based cross-sectional study among 340 women of reproductive age selected using multistage sampling technique. A semi-structured interviewer administered questionnaire was used to collect data on socio-demographic characteristics of respondents, IPTp uptake and reasons for not taking IPTp. Adherence was judged adequate if three or more doses of IPTp were taken, otherwise inadequate. Data were analyzed using descriptive statistics, Chi- square test and logistic regression model at $5 \%$ level of significance.

Results: Mean age of respondents was $28.8 \pm 5.2$ years, $96.5 \%$ were married, $19.4 \%$ had tertiary education, and $11.2 \%$ were from polygamous family. Uptake of IPTp was $74.2 \%$. The level of IPTp uptake was 12.5 and $41.0 \%$ among women with no formal and tertiary education respectively. A similar pattern of IPTp uptake was observed among women from monogamous (38.0\%) and polygamous (39.5\%) families. Women education, husband education and family type were associated with uptake of IPTp, however only husband education remained a predictor of uptake. Women whose husband had secondary education $(\mathrm{aOR}=4.1,95 \% \mathrm{Cl}: 1.66-10.06)$ and tertiary education ( $\mathrm{aOR}=4.8,95 \% \mathrm{Cl}$ : 1.76-12.90) were more likely to have IPTp uptake than those whose husbands had below secondary education.
\end{abstract}

Conclusion: Adequate IPTp uptake among women in their last pregnancy was below WHO recommendation. Intervention aimed at improving couple's education could facilitate increase in IPTp uptake in Ebonyi State.

Keywords: Malaria, Intermittent preventive treatment, Sulfadoxine/Pyrimethamine, Uptake, Nigeria

\footnotetext{
* Correspondence: chukwumau@gmail.com

${ }^{1}$ Nigeria Field Epidemiology and Laboratory Training Programme, Abuja,

Nigeria

${ }^{3}$ Department of Community Medicine, Alex Ekwueme Federal University

Teaching Hospital, Abakaliki, Ebonyi State, Nigeria

Full list of author information is available at the end of the article
}

(c) The Author(s). 2019 Open Access This article is distributed under the terms of the Creative Commons Attribution 4.0 International License (http://creativecommons.org/licenses/by/4.0/), which permits unrestricted use, distribution, and reproduction in any medium, provided you give appropriate credit to the original author(s) and the source, provide a link to the Creative Commons license, and indicate if changes were made. The Creative Commons Public Domain Dedication waiver (http://creativecommons.org/publicdomain/zero/1.0/) applies to the data made available in this article, unless otherwise stated. 


\section{Background}

Malaria in pregnancy has consequences for mother, fetus and newborn child which are largely preventable [1]. World Malaria Report 2018 reaffirms that, the realization of the two critical 2020 milestones of the WHO Global Technical Strategy for malaria to reduce case incidence and death rates by at least $40 \%$ from 2015 levels, might not be feasible [2]. In 2018, there were an estimated 219 million cases and 435,000 deaths from malaria globally and about $80 \%$ of these deaths were found in the WHO African Region and India [2]. Only seven countries accounted for $53 \%$ of all global malaria death of which Nigeria contributed 19\% [2].

Twenty-five million pregnant women are currently at risk of malaria, it accounts for over 10,000 maternal and 200, 000 neonatal deaths per year in sub-Saharan Africa [3]. Inadequate access and uptake of lifesaving malaria interventions which includes intermittent preventive treatment in pregnancy (IPTp) has been reported as a predisposing factor to maternal and infant morbidity and mortality [2].

In areas of stable malaria transmission in Africa, WHO recommends a package of intermittent preventive treatment (IPTp) with Sulfadoxine-Pyrimethamine (SP) and use of insecticide-treated nets (ITNs), together with effective case management of clinical malaria and anaemia to prevent morbidity and mortality due to malaria in pregnancy [4]. A minimum of three doses of SP, taken one month apart, commencing after quickening (approximately 18 weeks gestation) and routinely delivered at antenatal clinics has been recommended [4]. Among 33 African countries that reported IPTp coverage in $2018,22 \%$ of eligible pregnant women received the recommended three or more doses of IPTp, compared with $17 \%$ in 2015 and $0 \%$ in 2010 [2].

Nigeria adopted the IPTp strategy in year 2005 [5]. However, variation has been found in the level of IPTp uptake across the states in Nigeria. According to Nigeria Demographic and Health Survey 2018, the percentage of women who received at least one dose of SP was 63.6\%, (72.6\% urban and rural 58\%) but the proportion of women who took at least three doses of SP was reported as $16.6 \%$ (urban $20.7 \%$ and rural $14 \%$ ). The proportion of women who took at least three doses in Ebonyi State was $24.2 \%$ [6]. A household survey on IPT coverage among 1307 respondents that compared urban and rural areas of Enugu, Nigeria in 2012, found that uptake remained low at $13.7 \%$ [7]. Whereas, more parasitemia had been reported among pregnant women who did not received IPTp in Ebonyi State, there appears to be paucity of studies documenting the uptake levels of IPTp and exploring the factors associated with uptake [8]. We determined the level of IPTp uptake and factors influencing it among women of reproductive age residing in communities in Ebonyi State.

\section{Methods}

\section{Study area}

This study was conducted in Ebonyi State which is one the five states that make up the South East geopolitical zone in Nigeria. Ebonyi State has 13 Local Government Areas (LGA) and 142 communities. The 2019 projected population of Ebonyi State and population of women of reproductive age were $3,112,220$ and 684,688 respectively as obtained from the State Ministry of Health. Presently there are 556 health facilities both public and private in Ebonyi State comprising one tertiary health facility, 13 general hospitals, 6 mission hospitals, 417 primary health centers and 119 private hospitals/clinics [9]. Most of these health facilities offer maternal and child health related services such as ante natal care (ANC) and immunization services. The ANC attendance at health facilities with skilled providers was 70.3\% [6]. Ebonyi State is one of the states supported by the Presidential Malaria Initiative project. The project provides training for health workers, provides malaria preventive commodities including SP. During ANC clinics, SP is prescribed and dispensed at the health facility at no cost to the pregnant.

The predominant occupations in the state are farming and trading. Most communities in Ebonyi State engage in farming activities which increases the man-vector contact aiding malaria transmission. More so, the limestone excavations and quarrying activities in many of the communities create enabling environments for water accumulation and breeding of mosquitoes that transmit malaria.

\section{Study design and population}

We conducted a cross-sectional study among women of reproductive age $(N=340)$. We included women who had been residing in selected communities and had given birth in the past year prior to the survey. The women who were incapacitated or not disposed to respond to the interview were excluded.

\section{Sampling technique}

Multistage sampling technique was used to recruit respondents for the study. Two LGAs (Abakaliki and Ebonyi) were selected by balloting from a list of 13 LGAs in the state. In each of the LGAs, four communities were selected by balloting from Abakaliki LGA (Izziunuhu, Azuiyiokwu, Okpaugwu, and Timber Communities) and Ebonyi LGA (Aboffia, Kpirikpiri, Abakpa, and New Layout). The list of households in these communities were obtained from the immunization department of the selected LGAs. A total of 1041 households from the eight communities were obtained to serve as sampling frame. Eligible women were selected from each of the sampled households in the communities using systematic 
sampling technique until the allocated sample size was achieved. However, in any household where there was more than one eligible woman, the respondent was selected by balloting.

\section{Measurement of variables}

The dependent variable was IPTp uptake which was categorized based on the number of doses of IPTp they took during the pregnancy in the year preceding the survey. Those who did not take any IPTp were categorized as none, those who took less than three doses were categorized as inadequate uptake and those who took three doses and or more were categorized as having adequate uptake. To examine the determinants of IPTp uptake, we re-categorize the variable into two groups. None IPTp uptake and inadequate uptake were merged and categorized as inadequate while adequate uptake remained as $\geq 3$ doses.

\section{Data collection and analysis}

A semi-structured interviewer administered questionnaire was used to collect data on socio-demographic characteristics of respondents, uptake of intermittent preventive treatment for malaria in pregnancy, health facility type and spouse information. The data collection was conducted by trained research assistants. Data were analyzed with Statistical Package for Social Science (IBM SPSS) version 20. We examined the association between uptake of IPTp and sociodemographic characteristics using Chi Squared test. The variables that were significant at $10 \%$ in the bivariate analysis were included in the multiple logistic regression. We identified the predictors of IPTp uptake at $5 \%$ level of significance.

\section{Ethical considerations}

We obtained ethical approval from the Research and Ethics Committee of Ebonyi State Ministry of Health (approval reference number: SMOH/ERC/054/19). Written informed consents were obtained from all respondents after explaining the details of the study. Participation in the study was voluntary and the information obtained were handled with strict confidentiality.

\section{Results}

The mean age of the respondents was $28.8 \pm 5.2$ years. The 25-34 years age group constituted the majority $(65.0 \%)$ and most of the respondents were married 328 (96.5\%). Majority of the respondents (67.9\%) and their spouses $(55.0 \%)$ had attained secondary level education (Table 1).

Two hundred and forty-five women (74.2\%) took at least one dose of IPTp during the last pregnancy within a year prior to the study, whereas, $130(53.0 \%)$ took at least three doses (Table 2).
Table 1 Sociodemographic and reproductive characteristics of the respondents $(N=340)$

\begin{tabular}{|c|c|c|}
\hline Variable & Frequency & Percentage \\
\hline \multicolumn{3}{|l|}{ Age (years) } \\
\hline$<25$ & 69 & 20.3 \\
\hline $25-34$ & 221 & 65.0 \\
\hline$\geq 35$ & 50 & 14.7 \\
\hline \multicolumn{3}{|l|}{ Marital status } \\
\hline Married & 328 & 96.5 \\
\hline Not married & 12 & 3.5 \\
\hline \multicolumn{3}{|l|}{ Employment status } \\
\hline Employed & 301 & 88.5 \\
\hline Unemployed & 39 & 11.5 \\
\hline \multicolumn{3}{|c|}{ Respondents' education } \\
\hline No formal & 8 & 2.4 \\
\hline Primary & 35 & 10.3 \\
\hline Secondary & 231 & 67.9 \\
\hline Tertiary & 66 & 19.4 \\
\hline \multicolumn{3}{|l|}{ Husband education } \\
\hline No formal & 9 & 2.6 \\
\hline Primary & 43 & 12.7 \\
\hline Secondary & 187 & 55.0 \\
\hline Tertiary & 101 & 29.7 \\
\hline \multicolumn{3}{|l|}{ Family type } \\
\hline Monogamous & 292 & 85.9 \\
\hline Polygamous & 38 & 11.2 \\
\hline Single mother & 10 & 2.9 \\
\hline \multicolumn{3}{|l|}{ Parity } \\
\hline Primigravida & 51 & 15.0 \\
\hline Multigravida & 220 & 64.7 \\
\hline Grand multipara & 69 & 20.3 \\
\hline
\end{tabular}

Out of 40 respondents receiving ANC from tertiary health facility, $57.5 \%$ did not receive up to three recommended IPTp during pregnancy compared to those attending ANC in the other health facility types. Up to half of the those attending ANC in mission owned health facilities $(51 \%)$ received at least three doses of IPTp during pregnancy (Fig. 1).

Respondent's education $(p=0.002)$, the spouse level of education $(p<0.001)$ and family type $(\mathrm{p}=0.002)$ were found to be significantly associated with uptake of IPTp among the respondents at bivariate analysis (Table 3). However, when these were modelled in binary logistic regression, only husband education predicted uptake of IPTp. Respondents whose husbands had attained secondary education were 4 times more likely to take IPTp (adjusted odds ratio [aOR]:4.1; 95\% Confidence interval [CI]: 1.64-10.06) compared to those whose husbands 
Table 2 Uptake of intermittent preventive treatment (IPTp) among respondents

\begin{tabular}{lcl}
\hline Variable & Frequency & Percentage \\
\hline Took antimalaria in pregnancy in the year preceding the survey \\
Yes & 330 & 97.1 \\
No & 10 & 2.9 \\
Type of antimalaria used ( $n=330)$ & & \\
Sulfadoxine/Pyrimethamine (SP) & 245 & 74.2 \\
ACT/ Coartem & 24 & 7.3 \\
Chloroquine & 8 & 2.4 \\
Quinine & 2 & 0.6 \\
I don't know & 34 & 10.3 \\
I can't remember & 17 & 5.2 \\
Number of times SP was taken $(n=245)$ & \\
Once & 21 & 8.6 \\
Twice & 94 & 38.4 \\
Three times & 113 & 46.1 \\
More than three times & 17 & 6.9 \\
SP was taken at health facility (during ANC, $n=245)$ & \\
Yes & 240 & 98.0 \\
No & 5 & 2.0 \\
Type of health facility SP was received $(n=240)$ & 46.7 \\
Tertiary government owned & 40 & \\
Private mission owned & 112 & \\
Primary health centre & 50.8 \\
Private for-profit hospitals & 38 & \\
\hline
\end{tabular}

had attained primary education or less. Similarly, respondents whose husbands had attained tertiary education were 4.8 times more likely to take IPTp (aOR:4.8; 95\%CI: 1.76-12.90) compared to those whose husbands had attained primary education or less (Table 4).

\section{Discussions}

This study was on uptake of intermittent preventive treatment for malaria in pregnancy among women who had given birth in the past year prior to the survey, in selected communities in Ebonyi State. We found a relatively high uptake of at least one dose of IPTp among the respondents. This could be due to growing level of awareness of IPTp in the country. The finding in our study was higher than that reported in Enugu in 2012 among 1307 respondents [7]. It was also higher than the south east regional average uptake found in the 2015 Nigeria Malaria Indicator Survey which was conducted among 1338 respondents in each geo-political zone [10]. The uptake in our study was slightly higher than the 67.2\% reported for Ebonyi State in the 2018 Nigeria Demographic Health Survey [6]. It was also higher than other studies in South West Nigeria [11] and Mali [12] but lower than that reported in Ghana [13]. The higher uptake observed among the primary health facilities compared to the private and tertiary health facilities could be related to the practice observed in the state. Women tend to register for ANC early in facilities closer to them due to cost of services and transportation but register at the private or tertiary health facilities close to their delivery. The late registration at this hospital types could have accounted for the apparent lower level of

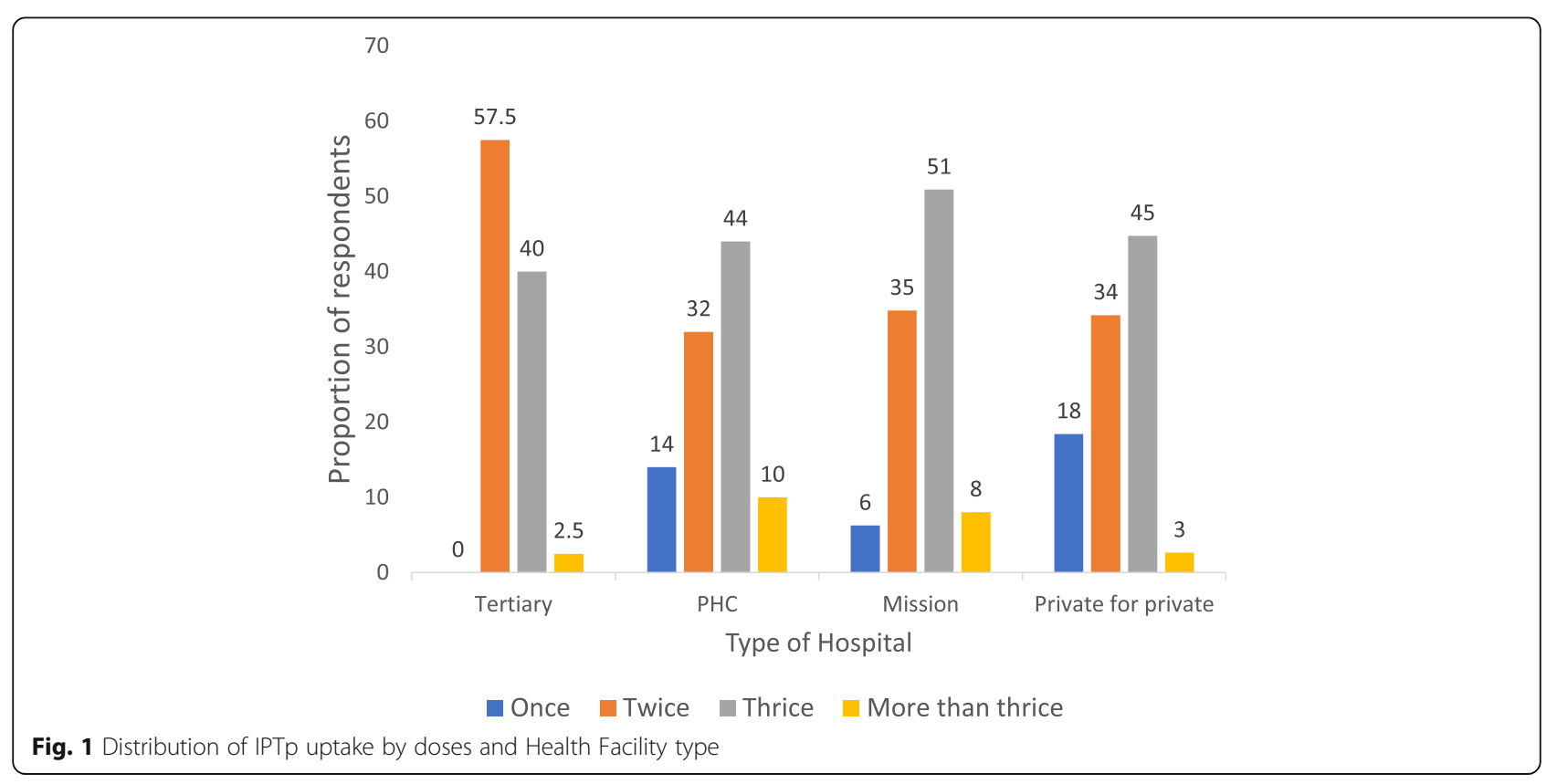


Table 3 Association between socio-demographic characteristics of the respondents and level of IPTp uptake

\begin{tabular}{|c|c|c|c|c|c|}
\hline \multirow[t]{2}{*}{ Variable } & \multicolumn{3}{|c|}{ Uptake of IPTp } & \multirow[t]{2}{*}{ Chi square $\left(x^{2}\right)$} & \multirow[t]{2}{*}{$p$ value } \\
\hline & None & Inadequate (1 or 2 doses) & $\begin{array}{l}\text { Adequate } \\
\text { ( } \geq 3 \text { doses) }\end{array}$ & & \\
\hline \multicolumn{6}{|l|}{ Age (years) } \\
\hline$<25$ & $17(24.6)$ & $31(44.9)$ & $21(30.4)$ & 6.407 & 0.171 \\
\hline $25-34$ & $61(27.6)$ & $72(32.6)$ & $88(39.8)$ & & \\
\hline$\geq 35$ & $17(34.0)$ & $12(24.0)$ & $21(42.0)$ & & \\
\hline \multicolumn{6}{|l|}{ Marital status } \\
\hline Married & $95(29.0)$ & 109 (33.2) & $124(37.8)$ & 4.888 & 0.087 \\
\hline Not currently married & $0(0.0)$ & $6(50.0)$ & $6(50.0)$ & & \\
\hline \multicolumn{6}{|l|}{ Respondent education } \\
\hline No formal & $3(37.5)$ & $4(50.0)$ & $1(12.5)$ & 21.144 & 0.002 \\
\hline Primary & $20(57.1)$ & $7(20.0)$ & $8(22.9)$ & & \\
\hline Secondary & $60(26.0)$ & 77 (33.3) & $94(40.7)$ & & \\
\hline Tertiary & $12(18.2)$ & $27(41.0)$ & $27(41.0)$ & & \\
\hline \multicolumn{6}{|l|}{ Husband education } \\
\hline No formal & $6(66.7)$ & $3(33.3)$ & $0(0.0)$ & 28.431 & $<0.001$ \\
\hline Primary & $23(53.5)$ & $13(30.2)$ & $7(16.3)$ & & \\
\hline Secondary & $45(24.1)$ & $64(34.2)$ & $78(41.7)$ & & \\
\hline Tertiary & $21(20.8)$ & $35(34.7)$ & $45(44.6)$ & & \\
\hline \multicolumn{6}{|l|}{ Family type } \\
\hline Monogamous & $92(31.5)$ & $89(30.5)$ & $111(38.0)$ & 16.581 & 0.002 \\
\hline Polygamous & $3(7.9)$ & $20(52.6)$ & $15(39.5)$ & & \\
\hline Single mothers & $0(0.0)$ & $6(60.0)$ & $4(40.0)$ & & \\
\hline
\end{tabular}

uptake. The relationship between time of first ANC attendance and uptake of IPTp has been reported. This however needs more exploration in our environment.

A 2018 survey that was done in eight sub-Saharan African countries among 18,603 respondents reported a low uptake of IPTp at 25.9\% [14]. The level of uptake in our study implies that the uptake of IPTp is improving and that pregnant women in Ebonyi State may likely have a better health seeking behavior towards prevention of malaria in pregnancy with the use of IPTp. It is important to note that Ebonyi State is one of the states supported by Presidential Malaria Initiative in Nigeria. The high prevalence may be due to the effect of the program activities on malaria control in the state. This finding could also be due to the nature of the study setting which were largely urban and the high level of education of the respondents. The proportion of women who had adequate uptake of IPTp (three or more doses) observed in our study was high but the WHO recommended target of $100 \%$ is yet to be achieved. The proportion of women who had adequate uptake was higher than that reported in a metropolitan area in Ghana [13].
The woman's level of education, husband's level of education and family type were associated with the uptake of IPTp. However, only husband's level of education was a predictor of adequate uptake of IPTp among respondents. This could be due to the influence of education on knowledge of IPTp and its benefits. The finding supports the importance of male involvement in antenatal care services. Male education is an important factor that could help improve antenatal care services use and IPTp uptake by pregnant women. Having secondary or tertiary education improved the odds of the uptake of IPTp by pregnant women by four folds. Contrary to our finding, Nigeria malaria indicator survey 2015 found that woman's education was a predictor of IPTp uptake [10]. A cross-sectional study conducted in south west Nigeria in 2012, and a qualitative study that was done in Uganda showed that lack of knowledge on the benefit of IPTp constituted a barrier to its uptake [15]'[16]. There is a tendency for the more educated to have more knowledge on IPTp, have access to health services, better risk perception, better income and adhere to recommendation. A cross sectional study in Kano, North West Nigeria in 2012 among 239 women found that advanced maternal age and higher level of education were predictors of IPTp 
Table 4 Predictors of adequate uptake of IPTp among the respondents

\begin{tabular}{|c|c|c|}
\hline Variable & Crude OR & Adjusted OR \\
\hline \multicolumn{3}{|l|}{ Age (years) } \\
\hline$<25$ & 1 & \\
\hline $25-34$ & $1.5(0.93-2.46)$ & \\
\hline$\geq 35$ & $1.7(0.87-3.13)$ & \\
\hline \multicolumn{3}{|c|}{ Respondent education } \\
\hline Primary or less & 1 & \\
\hline Secondary & $2.6(1.1-5.66)$ & $1.4(0.58-3.32)$ \\
\hline Tertiary & $2.6(1.1-6.33)$ & $1.3(0.46-3.63)$ \\
\hline \multicolumn{3}{|l|}{ Family type } \\
\hline Monogamous & 1 & \\
\hline Polygamous & $1.1(0.60-1.90)$ & $1.2(0.58-2.47)$ \\
\hline Single mother & $1.1(0.37-3.20)$ & $0.8(0.21-3.07)$ \\
\hline \multicolumn{3}{|l|}{ Husband education } \\
\hline Primary or less & 1 & \\
\hline Secondary & $4.6(2.26-9.37)$ & $4.1(1.64-10.06)$ \\
\hline Tertiary & $5.2(2.45-10.88)$ & $4.8(1.76-12.90)$ \\
\hline \multicolumn{3}{|l|}{ Parity } \\
\hline Primigravida & $0.9(0.46-1.72)$ & \\
\hline Multigravida & $1.6(0.97-2.53)$ & \\
\hline Grand multipara & 1 & \\
\hline
\end{tabular}

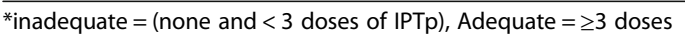

uptake [17]. Maternal education did not however predict uptake in our study.

It is important to note that high proportion of pregnant women took their SP at the health facility under direct observation of the health worker. This could have contributed to the high level of uptake observed. This also suggests availability of SP at the health facility which could have encouraged the uptake. It has also been reported that early initiation of ANC was associated with good uptake of SP [13].

A limitation of this study was the possibility of a recall bias. To minimize this, the respondents were shown pictures of Sulfadoxine/Pyrimethamine package to enable them identify the medicine and correctly recall taking it. In addition, the study included only women who had given birth in the past year prior to the survey to aid their recall hence may not be representative of the target population. Information on the gestational age at first ANC visit and the number of ANC visits were not captured in this study. This could have enabled more exploration on the factors that influenced uptake of the IPTp.

\section{Conclusion}

Adequate IPTp uptake among women in their last pregnancy was below WHO recommendation. Age, family type, respondent's education, parity and husband education were associated with uptake of IPTp among pregnant women. However, husband education remained a determinant of IPTp uptake among the women in this study. We recommend that male education should be encouraged. This would probably have a positive influence on uptake of IPTp.

\section{Abbreviations}

ANC: Antenatal Care; ERC: Ethics and Research Committee; IPTp: Intermittent Prophylactic Treatment in Pregnancy; ITN: Insecticide Treated Nets;

SMOH: State Ministry of Health; SP: Sulfadoxine/Pyrimethamine; WHO: World Health Organization

\section{Acknowledgements}

The authors are grateful to the Africa Field Epidemiology Network and Nigeria Field Epidemiology and Laboratory Training Programme for their support in preparing this manuscript.

Ethical approval and consent to participate

We obtained ethical approval from the Research and Ethics Committee of Ebonyi State Ministry of Health (approval reference number: SMOH/ERC/054/ 19). Written informed consents were obtained from all respondents after explaining the details of the study. There were no minor among the respondents. Participation in the study was voluntary and the information obtained were handled with strict confidentiality.

\section{Authors' contributions}

ACO: Conceptualized the study, design, implemented data acquisition, drafted the initial manuscript.

AJO: supervised the study, made substantial revision to the draft manuscript. CDU: Data analysis and interpretation, substantial revision of the initial manuscript.

EAB: made substantial revision to the draft manuscript.

TD: made substantial revision to the draft manuscript.

ASA: made substantial revision to the draft manuscript.

IOA: Supervised the overall study, made substantial revision to the draft manuscript.

All authors read and approved the final version of the manuscript for publication.

\section{Funding}

The authors did not receive any funding for the study.

\section{Availability of data and materials}

The datasets used and/or analysed during the current study are available from the corresponding author on reasonable request.

\section{Consent for publication}

Not applicable.

\section{Competing interests}

The authors declare that they have no competing interests.

\section{Author details}

${ }^{1}$ Nigeria Field Epidemiology and Laboratory Training Programme, Abuja, Nigeria. ${ }^{2}$ Department of Epidemiology and Medical Statistics, Faculty of Public Health, College of Medicine, University of Ibadan, Ibadan, Nigeria. ${ }^{3}$ Department of Community Medicine, Alex Ekwueme Federal University Teaching Hospital, Abakaliki, Ebonyi State, Nigeria. ${ }^{4}$ Department of Community Medicine, Ahmadu Bello University, Zaria, Kaduna State, Nigeria.

Received: 10 June 2019 Accepted: 25 November 2019 Published online: 02 December 2019

\section{REFRENCES}

1. Hill J, Hoyt J, Eijk AM, Mello-guyett LD, Kuile FO, Steketee R, et al. Factors Affecting the Delivery, Access, and Use of Interventions to Prevent Malaria 
in Pregnancy in Sub-Saharan Africa: A Systematic Review and MetaAnalysis. PLoS One. 2013;10(7):3.

2. World Health Organization. World Malaria Report 2018 [Internet]. Geneva, Switzerland; 2018. Available from: https://apps.who.int/iris/bitstream/ handle/10665/275867/9789241565653-eng.pdf?ua=1

3. Schatz-Dunn J, Nour N. Malaria and Pregnancy: A Global Health Perspective. Rev Obs Gynaecol. 2009;2(3):186-92.

4. World Health Organization. Malaria Policy Advisory Committee Meeting Report [Internet]. 2019. Available from: http://iris.wpro.who.int/handle/1 0665.1/10945

5. Federal Ministry of Health, National Malaria Control Programme, Abuja, Nigeria. Strategic Plan 2009-2013, A Road Map for Malaria Control in Nigeria DRAFT 16 June 2008. 2013;(2008):1-39.

6. National Population Commission Nigeria I. Nigeria Demographic and Health Survey 2018: Key Indicators. Abuja, Nigeria and Rockville, Maryland, USA; 2019

7. Onoka CA, Hanson K, Onwujekwe OE. Low coverage of intermittent preventive treatment for malaria in pregnancy in Nigeria: demand-side influences. Malar J. 2012;11(1):82.

8. Nwali MI, Umeora OUJ, Ozumba BC, Onoh RC, Ezeonu POAU. Anemia Among Unbooked Parturients With Asymptomatic Malaria Parasitemia At A Tertiary Institution Southeast Nigeria. J Med Dent Sci. 2014;13(6):54-7.

9. Ebonyi State Goverment_ Ministry of Health [Internet]. AN OVERVIEW OF THE MINISTRY. Abakaliki; 2019 [cited 2019 Mar 2]. Available from: http:// www.ebonyistate.gov.ng/Ministry/Health/

10. National Malaria Elimination Programme. Nigeria Malaria Indicator Survey (MIS), 2015 [Internet]. Abuja Nigeria; 2015. Available from: https:// dhsprogram.com/pubs/pdf/MIS20/MIS20.pdf

11. Akinleye SO, Falade CO, Ajayi IO. Pregnancy and Childbirth Knowledge and utilization of intermittent preventive treatment for malaria among pregnant women attending antenatal clinics in primary health care centers in rural southwest, Nigeria: a cross-sectional study. BMC Pregnancy Childbirth. 2009; 9:1-9.

12. Hurley EA, Harvey SA, Rao N, Diarra NH, et al. PLoS One. 2016;1 (8):1-17.

13. Amankwah S, Anto F. Factors Associated with Uptake of Intermittent Preventive Treatment of Malaria in Pregnancy: A Cross-Sectional Study in Private Health Facilities in Tema Metropolis, Ghana. J Trop Med [Internet]. $2019: 1-11$. Available from: https://www.hindawi.com/journals/jtm/2019/92 $78432 /$

14. Yaya S, Uthman O, Amouzou A, Bishwajit G. Use of Intermittent Preventive Treatment among Pregnant Women in Sub-Saharan Africa: Evidence from Malaria Indicator Surveys. Trop Med Infect Dis. 2018;3(1):18.

15. Amoran $\mathrm{OE}$, Ariba $\mathrm{AA}$, lyaniwura CA. Determinants of intermittent preventive treatment of malaria during pregnancy (IPTp) utilization in a rural town in Western Nigeria. Reprod Health. 2012;9(1):12.

16. Rassi C, Graham K, King R, Ssekitooleko J, Mufubenga P, Gudoi SS. Assessing demand - side barriers to uptake of intermittent preventive treatment for malaria in pregnancy: a qualitative study in two regions of Uganda. Malar J. 2016:1-14.

17. Iliyasu Z, Gajida AU, Galadanci HS, Abubakar IS, Baba AS, Jibo AM, et al. Adherence to intermittent preventive treatment for malaria in pregnancy in urban. Pathog Glob Heal. 2012;106(6):323-9.

\section{Publisher's Note}

Springer Nature remains neutral with regard to jurisdictional claims in published maps and institutional affiliations.

Ready to submit your research? Choose BMC and benefit from:

- fast, convenient online submission

- thorough peer review by experienced researchers in your field

- rapid publication on acceptance

- support for research data, including large and complex data types

- gold Open Access which fosters wider collaboration and increased citations

- maximum visibility for your research: over $100 \mathrm{M}$ website views per year

At BMC, research is always in progress.

Learn more biomedcentral.com/submissions 